\title{
ARTICLE
}

\section{Archaeometric analysis of architectural ceramics form the site "Khustiin bulag" Tuv province, Mongolia}

\author{
Suvd-Erdene Byambasuren ${ }^{1}$, Ishtseren Lochin ${ }^{2}$, Tengis Saran ${ }^{1}$ \\ Orgil Baatarjav ${ }^{1}$, Eregzen Gelegdorj ${ }^{2}$ and Saran Solongo ${ }^{1 *}$ \\ ${ }^{1}$ Department of Applied Physics, Institute of Physics and Technology \\ Mongolian Academy of Sciences, Ulaanbaatar, Mongolia \\ ${ }^{2}$ Department of Xiongnu and Ancient States Studies, Institute of Archaeology \\ Mongolian Academy of Sciences, Ulaanbaatar, Mongolia
}

ARTICLE INFO: Received: 25 Oct, 2019; Accepted: 16 Jun, 2020

\begin{abstract}
A series of architectural ceramics, including roof tiles and bricks from the excavation site at Khustyn Bulag, Mungunmorit soum, Tuv aimag (province) of Mongolia were subjected to detailed archaeometric analysis. We present here results of Fourier-transform infrared spectroscopy (FT-IR), Scanning electron microscopy (SEM-EDS) and Thermogravimetric analysis (TGA) and their potential to determine the composition of brick samples from one excavation site, and their firing temperatures. In addition, yellow ochre, which is a natural earth rock pigment that contains hydrated iron oxide and represents the most common pigment of antiquity, was revealed at this excavation site. The mineral composition of ochres will be determined and the possible use of it will be discussed.
\end{abstract}

Keywords: ceramic; ochres; clay mineral; firing temperature; SEM-EDS; FT-IR; TGA;

\section{INTRODUCTION}

Determining the composition of clayware and raw materials, production techniques and minerals occurring during firing is important for the study of archaeological and cultural studies. Archaeological finds, such as earthenware are regarded as an important tool that contains information about the timeframe, technology and origin. In fact, the application of the techniques of chemistry, physics, geology, and materials science provide a basis for understanding many questions about manufacturing techniques, history of technology, production organization, functional relationships between specific resource manufacturing combinations, and patterns of local, regional or extra-regional distribution of pottery [1].

While for the age determination of heated ceramic samples thermoluminescence (TL) was used; archeometric methods such as Fouriertransform infrared spectroscopy (FT-IR), X-ray diffraction, scanning electron microscope (SEM-EDS) and thermogravimetric analysis (TGA) are commonly combined together to

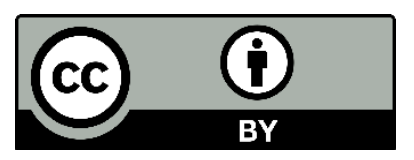

The Author(s). 2020 Open access This article is distributed under the terms of the Creative Commons Attribution 4.0 International License (https://creativecommons.org/licenses/by/4.0/), which permits unrestricted use, distribution, and reproduction in any medium, provided you give appropriate credit to the original author(s) and the source, provide a link to the Creative Commons license, and indicate if changes were made. 
determine the mineral composition and technological processes [2-3]. For decades, IR spectroscopy has been one of the frequently used methods to investigate the structure, bonding and chemical properties of clay minerals [4]. The examination of ancient pottery with an analytical SEM is, therefore, valuable for characterizing and distinguishing between the traditions in ceramic technology in antiquity because information is obtained on both extent of vitrification and firing temperature [5].

The compositional analysis of ceramic materials in archaeological studies is carried out with the purpose of understanding how the ceramic might have been produced and used, and also to determine the location and techniques involved in its manufacture. Mineralogical analysis of ancient pottery is particularly useful in the understanding of the manufacturing process, and appropriate techniques may provide information about temper addition, oxidation-reduction conditions and temperatures of firing.

Clay minerals are determined by the temperature and duration of firing. During firing, the minerals change their structure, they decompose and finally new minerals are formed [6]. In archaeology, the firing temperature is considered to be the benchmark of the technological level of ancient society. Such an

\section{MATERIALS AND METHODS}

\section{Research materials}

The site from the Khustyn Bulag, Mungunmorit soum in Tuv aimag was previously described elsewhere [13], [14] and architectural samples were collected during the excavations carried out by the Institute of Archaeology of the Mongolian Academy of approach originated from the characterization of contemporary ceramic manufacturing [7]. During firing, the color of the sample changes, which is related to the iron $(\mathrm{Fe})$ content of the material. Iron oxide produces hematite at temperatures higher than $600^{\circ} \mathrm{C}$, and at $>890^{\circ} \mathrm{C}$ it produces magnetite [8]. The authors [9-10] believe that the firing at about $600-800^{\circ} \mathrm{C}$, was sufficient for decomposing calcareous material.

A series of architectural ceramics, including roof tiles and bricks from the excavation site at Khustyn Bulag, Mungunmorit soum, Tuv aimag were previously subjected to rehydroxylation dating of bricks, which gave a date of $2200 \pm 20$ years, proving that the construction materials were from the Xiongnu period [9]. Analytical methods conducted to determine the mineral composition, production techniques and origin of the clay $[9,11,12]$ revealed the need for further examining the samples. Particularly, a detailed archaeometric analysis might also verify the presence and impact of calcite $\left(\mathrm{CaCO}_{3}\right)$ on the rehydroxylation dating method. Therefore, in this work, TGA together with microanalysis (SEM-EDS) and FT-IR were used for characterization of the construction materials excavated at a certain archaeological site, as well the characterization of the different layers of the roof tiles.

Sciences. Ceramics: roof tiles MM1, MM2 and MM3, tapestry brick MM4 and after refiring at $500^{\circ} \mathrm{C}$ for 4 hours are shown in Figure 1. Ochre pigment sample $\mathrm{MM} \mathrm{N}$ was fired at $500^{\circ} \mathrm{C}$, $700^{\circ} \mathrm{C}$ and $900^{\circ} \mathrm{C}$ for 1 hour and is shown in Figure 2. 


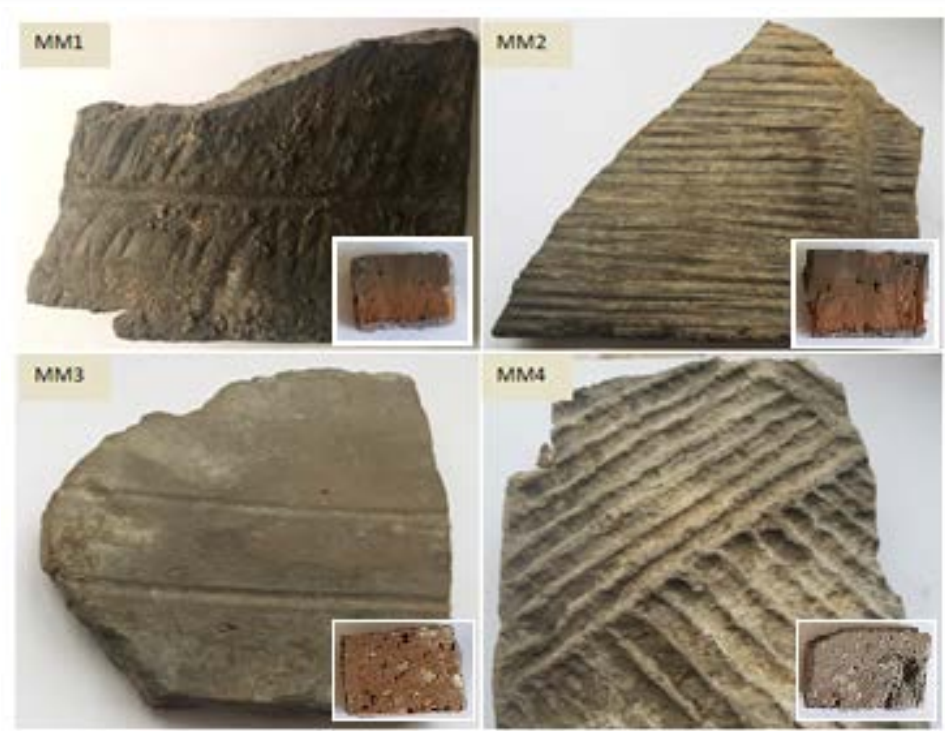

Figure 1. Roof tiles of MM1, MM2, MM3 and brick of MM4; inset shows the corresponding fragments after refiring at $500^{\circ} \mathrm{C} \mathrm{for} 4 \mathrm{~h}$

The samples were heated at $500^{\circ} \mathrm{C}$ for 4 hours. Initially, the color was grey, however, after refiring at $500^{\circ} \mathrm{C}$ for 4 hours, the color of samples MM1, MM2, MM3 turned red, while the color of the MM4 sample became grey, as can be seen from the insets in Figure 1.

Figure 2 shows ochre samples after heating at $500^{\circ} \mathrm{C}, 700^{\circ} \mathrm{C}$ and $900^{\circ} \mathrm{C}$ for 1 hour.

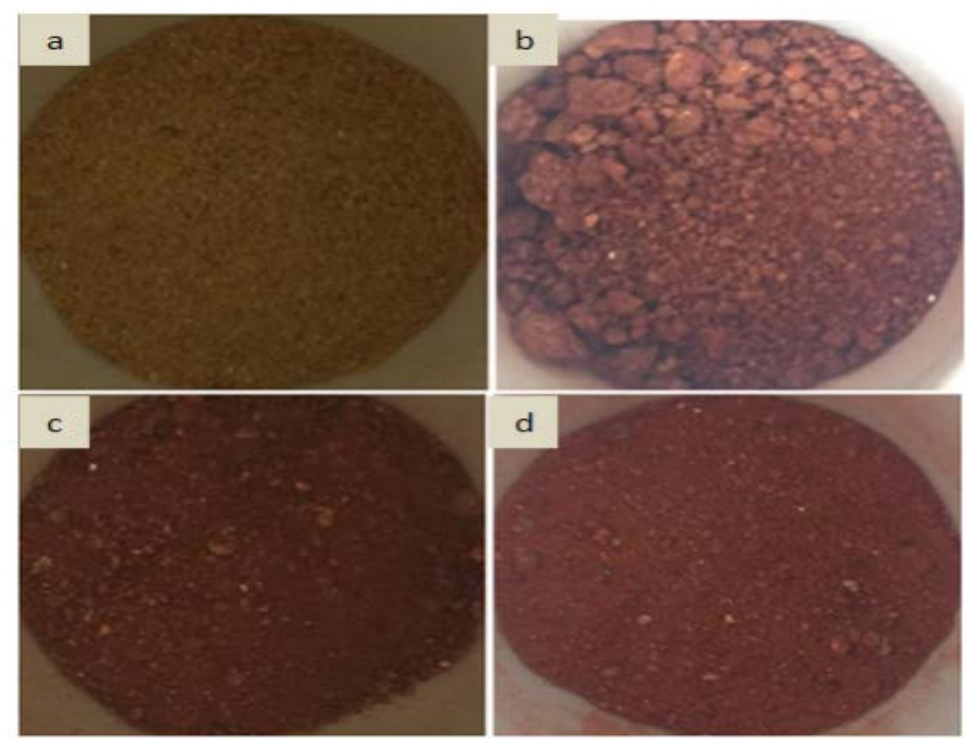

Figure 2. Ochre pigments sample (a) MM_N raw, (b), (c), (d) refired at $500^{\circ} \mathrm{C}, 700^{\circ} \mathrm{C}, 900^{\circ} \mathrm{C}$

Water evaporates and the color changes when the hydrated iron oxide is heated.

\section{TGA analysis}

Thermogravimetric analysis is a technique in which the mass of a substance is monitored as a function of temperature of time, in as much as the sample specimen is subjected to a controlled temperature program in a controlled atmosphere. The powders of each layer were ground in a mortar to a high degree of fineness. TGA analysis was then performed on the fine powders using a TGA-2100D from Analytical Technologies Limited. Temperatures were probed in the range between room temperature (RT) to $900^{\circ} \mathrm{C}$ at a heating rate of $10^{\circ} \mathrm{C} \mathrm{min}{ }^{-1}$, in a flowing nitrogen atmosphere at $100 \mathrm{ml} / \mathrm{min}$. For data analysis the software from TGA-2100D was used. 


\section{FT-IR analysis}

The firing temperature of the samples was determined from the FT-IR (IR) spectra using the following procedure [10]. FT-IR was recorded using an IR Prestige spectrometer. Spectra of powdered samples of the pottery were obtained using $\mathrm{KBr}$ disks. The disks were prepared using $1 \mathrm{mg}$ of the sample in $100 \mathrm{mg}$ of $\mathrm{KBr}$. The transmission spectra obtained were in the range of $4000-400 \mathrm{~cm}^{-1}$.

\section{RESULTS AND DISCUSSION}

\section{TGA analysis}

TGA is a technique when a material is heated, its weight either increases or decreases. The mass loss due to the thermal process was determined by thermogravimetric analysis and the peak intervals of the dehydration and dehydroxylation were determined accordingly [7]. When heated, clays show significant mass
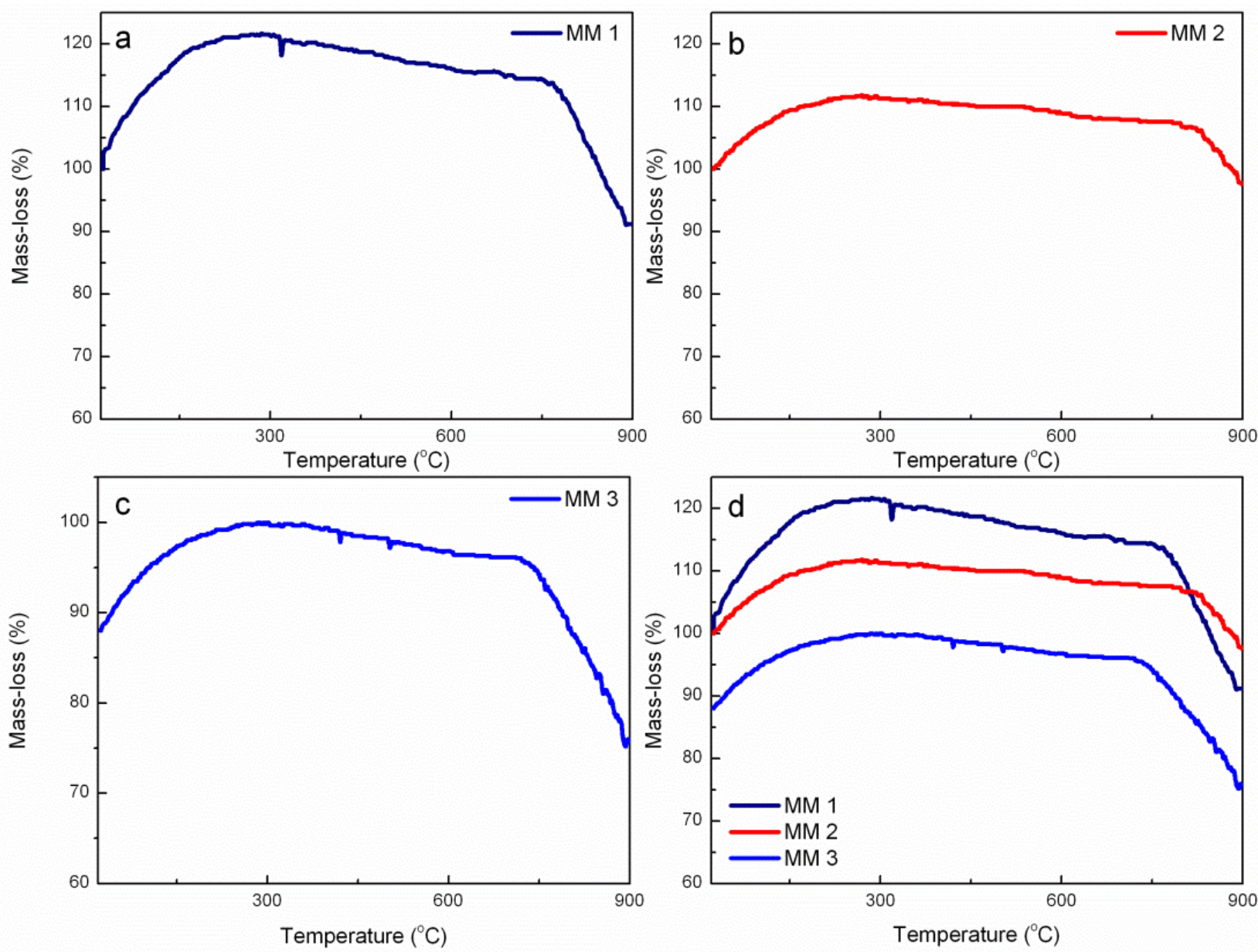

Figure 3. Representative TGA curves of samples MM1, MM2 and MM3 
Table 1. Thermal data in TGA of samples

\begin{tabular}{|c|c|c|c|}
\hline \multirow{2}{*}{ Sample code } & Mass increase, $\%$ & \multicolumn{2}{|c|}{ Weight loss, \% } \\
\cline { 2 - 4 } & $\left(20 \sim 350^{\circ} \mathrm{C}\right)$ & $\begin{array}{c}\text { Dehydroxylation } \\
\left(350 \sim 600{ }^{\circ} \mathrm{C}\right)\end{array}$ & $\begin{array}{c}\text { Decomposition of calcite } \\
\left(700 \sim 800{ }^{\circ} \mathrm{C}\right)\end{array}$ \\
\hline MM1 & 20 & 3 & 4 \\
\hline MM2 & 9 & 2 & 1 \\
\hline MM3 & 12 & 3 & 3 \\
\hline MM1 core & 12 & 3 & 1 \\
\hline MM1 outer & 6 & 11 & 14 \\
\hline MM1 inner & 2 & 6 & 9 \\
\hline
\end{tabular}

The mass loss due to dehydration (20, 9 and $12 \%)$, dehydroxylation $(3,2$ and $3 \%$ ) and due to decomposition of carbonates (4 and 9\%) are shown in Table 1. Only samples MM1, MM3 contain calcite; the presence of calcite decomposition was observed in the $700-800^{\circ} \mathrm{C}$ region. For samples MM1, MM2 and MM3 there was no mass loss relative to a particular region and further decay continued.

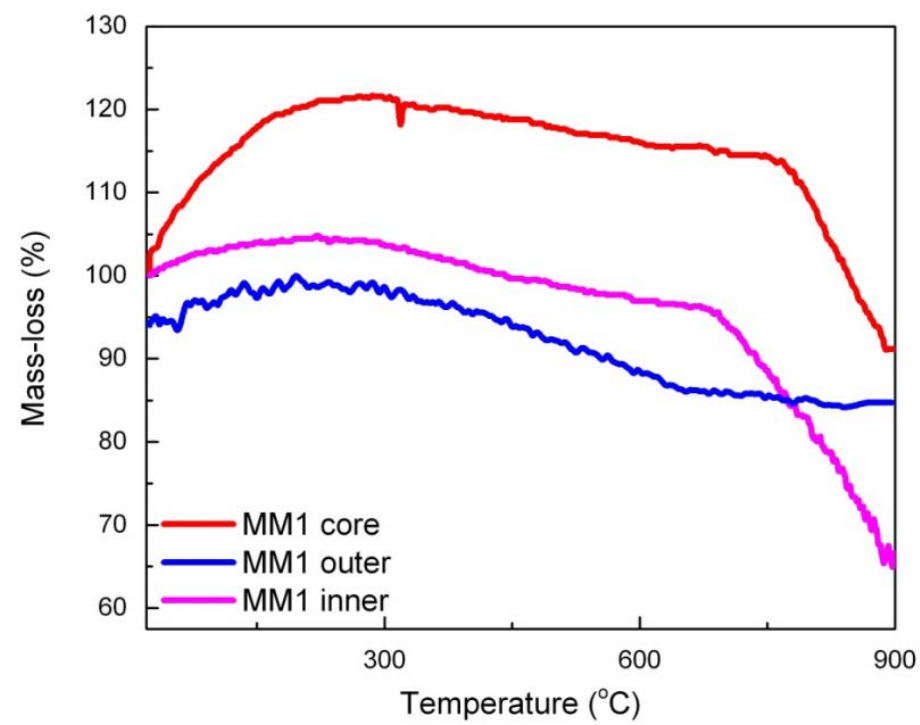

Figure 4. Representative TGA curves of sample MM1 (core, outer surface, inner surface)

According to [7], the outer surface, core and inner surface of the sample MM1 were also measured using thermogravimetry; the results are shown in Figure 4. The conventional statement says: if the sample contains calcite, the firing temperature was below $800^{\circ} \mathrm{C}$ [7]; the presence of calcite is observed for the inner surface and core. However, for the outer surface no calcite decomposition was observed. It should be noted that the outer surface was grey colored with hard surface, while the core and inner surface of sample MM1 were red-brown.

\section{FT-IR measurements}

FT-IR is a spectroscopy technique that is typically used to determine the functional structure of organic chemicals. It is advantageous in that it can reveal the presence of organic and inorganic substances [16]. The spectras of roof tile samples MM1, MM2 and MM3 along with brick sample MM4 were processed. Figure 4 shows the results of FT-IR measurements. 

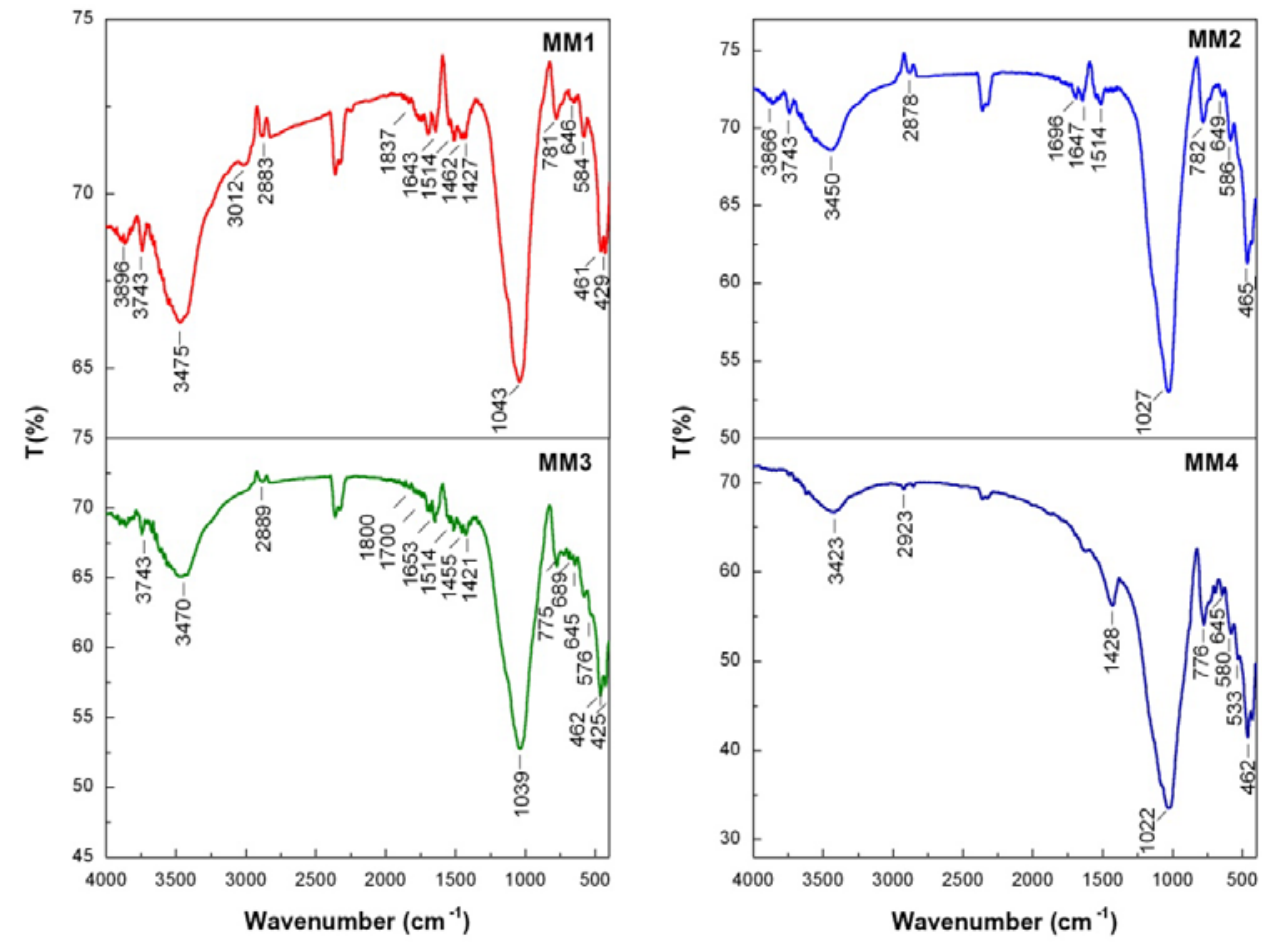

Figure 5. FT-IR results of samples MM1, MM2, MM3 and MM4

The spectra revealed microline and magnetite at $461 \mathrm{~cm}^{-1}, 584 \mathrm{~cm}^{-1}$ [6], quartz at $775 \mathrm{~cm}^{-1}$, and organic compounds at $2883 \mathrm{~cm}^{-}$ 1; the bands at $1643 \mathrm{~cm}^{-1}, 3450 \mathrm{~cm}^{-1}, 3743 \mathrm{~cm}^{-1}$ are assigned to $\mathrm{O}-\mathrm{H}$ stretching of inter layer and inner $\mathrm{O}-\mathrm{H}$ group of absorbed water $(\mathrm{O}-\mathrm{H}-\mathrm{O}$ bend). The band at $3896 \mathrm{~cm}^{-1}$ revealed an inter layer O-H group, which was detected in samples MM1 and MM2, but not yet detected in samples MM3 and MM4. Furthermore, a band in the region of $3423 \mathrm{~cm}^{-1}$ was detected in sample MM4, which was not detected in the other samples.

[17-18] proposed that calcite decomposition occurs at $600-800^{\circ} \mathrm{C}$. In our samples MM1, MM3 and MM4, a low intensity band and calcite band were detected around $1427 \mathrm{~cm}^{-1}$, no calcite was observed in MM2. TGA measurements detected a decomposition at around $700-800^{\circ} \mathrm{C}$ for ceramic samples.

The FT-IR spectra recorded a low intensity absorption band at $584 \mathrm{~cm}^{-1}$ for samples MM1, MM2 and MM3 and medium intensity band for MM4 turned out to be magnetite. A medium intensity hematite band at $584 \mathrm{~cm}^{-1}[6,15]$ was observed in sample MM4. The absorption band at $1043 \mathrm{~cm}^{-1}$ revealed the production temperatures for MM1 and MM2 as $700^{\circ} \mathrm{C}$ and $900^{\circ} \mathrm{C}$ for MM3 and MM4 [19]. It must be noted that after the RHX measurements were carried out at $500^{\circ} \mathrm{C}$, the color of tiles (MM1, MM2, MM3) became red and the brick (MM4) dark blue.

\section{Ochre analysis}

Natural iron-rich oxides provided redyellow-brown paints and dyes for a wide range of antique application, including but in no way limited to rock art paintings, pottery, wall paintings and cave art, and human tattoos. Generally speaking, ochres are natural earth pigments varying from dull yellow to red and brown. The colour shown by ochres depends on the nature of the iron oxide chromophore. Thus, the darker red ochres richer in hematite, $\mathrm{Fe}_{2} \mathrm{O}_{3}$, while the paler, yellow ochres mainly contain hydrated iron oxide, goethite, $\mathrm{Fe}_{2} \mathrm{O}_{3} \cdot \mathrm{H}_{2} \mathrm{O}$ or $\mathrm{FeOOH}[20]$.

Ochres is a natural earth rock pigment contains hydrated iron oxide and ranges in various color from red, yellow to deep orange or brown. Color changes are observed by heating ochre: pigments were fired at $500^{\circ} \mathrm{C}$, $700^{\circ} \mathrm{C}$ and $900^{\circ} \mathrm{C}$ for 1 hour and the mineral composition was measured using FT-IR. Furthermore, this is the first time that ochre samples from the Mongolian ancient architectural ceramics were examined. 

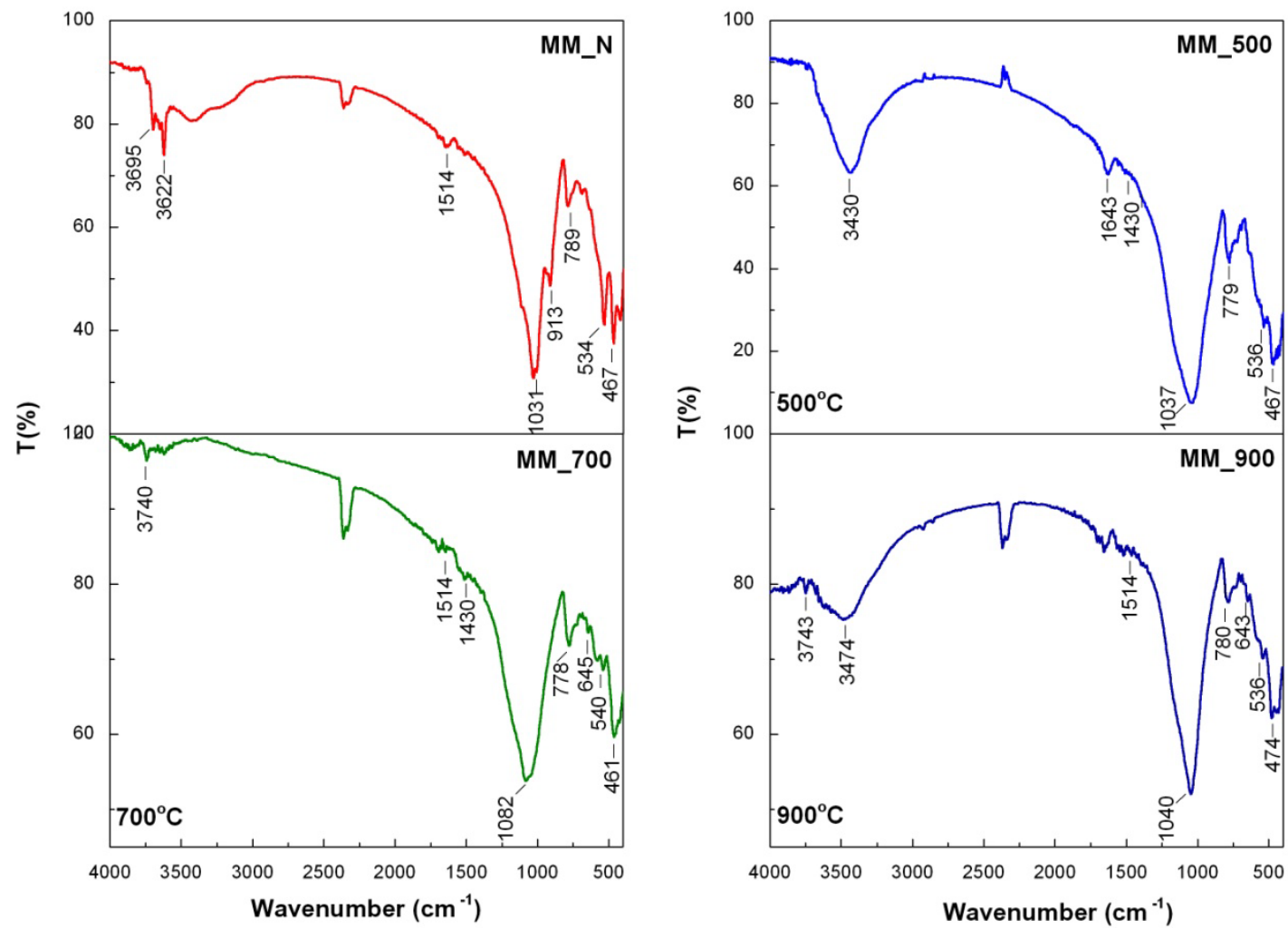

Figure 6. FT-IR spectra of: Ochre pigments sample (a) MM_N raw, (b), (c), (d) refired at $500^{\circ} \mathrm{C}, 700^{\circ} \mathrm{C}, 900^{\circ} \mathrm{C}$

The FT-IR spectra recorded the absorption bands at $431 \mathrm{~cm}^{-1}$ assigned to illite (O-M-O) [2], $3453 \mathrm{~cm}^{-1}$ indicated inter layer O$\mathrm{H}$, and absorption bands at $778 \mathrm{~cm}^{-1}$ and 797 $\mathrm{cm}^{-1}[16,21]$ indicated (Si-O). The spectra of ochre sample MM_N revealed high intensity peaks at $913 \mathrm{~cm}^{-1}, 1031 \mathrm{~cm}^{-1}$ indicated AI-OH and Illite stretching and the weak intensity band at $3622 \mathrm{~cm}^{-1}$ is due to $\mathrm{O}-\mathrm{H}$ stretching of illite (O-Hstr) [22]. For sample MM_500, weak intensity absorption bands at $1643 \mathrm{~cm}^{-1}, 2880$ $\mathrm{cm}^{-1}$ indicated absorbed water (O-H-O bend) and organic compounds respectively. The high intensity peak at $1082 \mathrm{~cm}^{-1}$ in sample MM_700 indicated a presence of quartz.
High intensity peaks were observed for samples MM_N and MM_500 and medium intensity peaks were observed for samples MM_700 and MM_900 at $465 \mathrm{~cm}^{-1}$ and $534 \mathrm{~cm}^{-}$ ${ }^{1}$, indicating microcline and hematite [6]. As a result of this observation it is possible to maintain that the high iron content in the ceramic was used for pigmentation.

\section{SEM-EDS analysis}

A scanning electron microscope provides detailed surface information by tracing a sample in a raster pattern with an electron beam. The typical SEM image of the selected MM1 and MM4 samples are shown in Figure 7 [9]. 

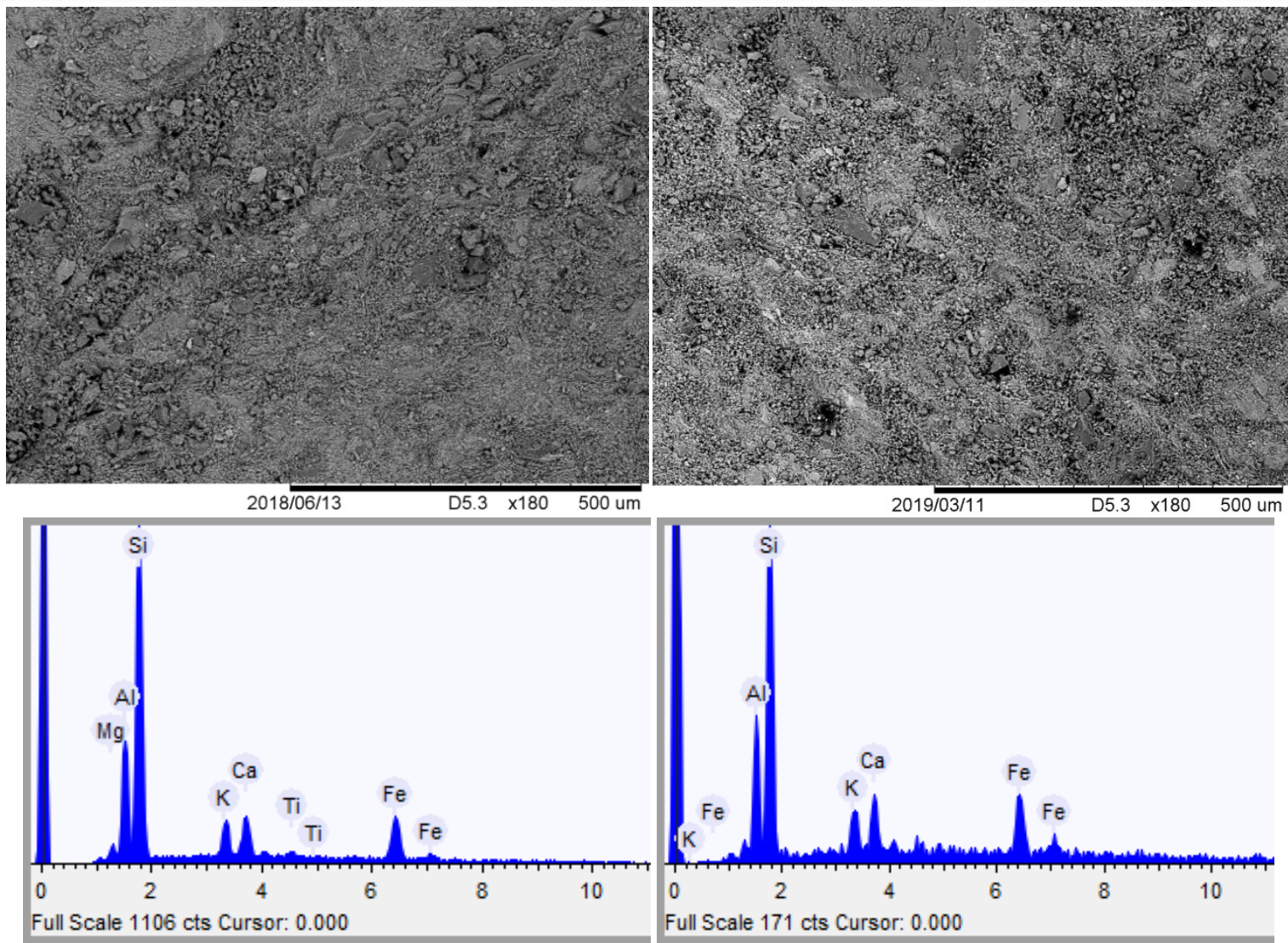

Figure 7. SEM-EDS Measurements: left MM1, right MM4

Table I. Results of SEM-EDS measurements

\begin{tabular}{|c|c|c|}
\hline \multirow{2}{*}{ Element } & \multicolumn{2}{|c|}{ Weight, \% } \\
\cline { 2 - 3 } & MM1 & MM4 \\
\hline $\mathrm{Mg}$ & 1.8 & \\
\hline $\mathrm{Al}$ & 13.9 & 13.4 \\
\hline $\mathrm{Si}$ & 40.7 & 36.3 \\
\hline $\mathrm{K}$ & 6.9 & 6.9 \\
\hline $\mathrm{Ca}$ & 7.7 & 9.5 \\
\hline $\mathrm{Ti}$ & 1.8 & \\
\hline $\mathrm{Fe}$ & 27.1 & 33.8 \\
\hline
\end{tabular}

A high concentration of iron was confirmed in the clay sample, which is in agreement with the results of IR measurements, and additionally, the clay sample was identified as illite $\left(\mathrm{KAl}_{2} \mathrm{Si}_{4} \mathrm{O}_{10}\right)$.

\section{CONCLUSIONS}

The architectural samples collected from the excavation site "Khustyn bulag", Mungunmorit soum, in Tuv aimag were investigated using TGA, FT-IR, and SEM-EDS to determine the firing temperatures and production techniques. The following conclusions were made.
1. It is advantageous to combine the TGA, FT-IR, and SEM-EDS methods to determine the production techniques. FT-IR measurements revealed the possibility that MM1 and MM2 samples were manufactured at $700^{\circ} \mathrm{C}$, while samples MM3 and MM4 were manufactured at $900^{\circ} \mathrm{C}$, however FT-IR method 
is more suitable for determining the mineral composition of the sample.

2. TGA measurements revealed that samples MM1 and MM3 were manufactured at below $800^{\circ} \mathrm{C}$, whereas sample MM2 was manufactured at $700^{\circ} \mathrm{C}$. Measurements of the samples from different layers of the roof tile MM1 revealed evident differences in the results. These detailed thermogravimetric results provided us information about the variations in the clay paste during the manufacturing period and also the possible variations in firing.

\section{REFERENCES}

1. Jose Miquel Herrero., Marius Vendrell., (2012). "International Seminar on Archaeometry and Cultural Heritage the contribution of Mineralogy” p. 30.

2 De Benedetto, G. E., Laviano, R., Sabbatini, L., Zambonin, P. G., (2002). "Infrared spectroscopy in the mineralogical characterization of ancient pottery” Journal of Cultural Heritage 3, pp. 177-186.

3 Tite, M.S., (2008). "Ceramic production, provenance and use a review" Archaeometry 50, 2, pp. 216-231.

Madejova, J., (2003). "FT-IR techniques in clay mineral studies” Vibration spectrometry 31, pp.1-10.

5 Raja Annamalia, G., Senthulkumar, G., Jebasingh Kores., and Ravisankar, R., (2017). "Determination of Manufacturing Process and Chemical Analysis of Archaeological Excavated from Kavapatti, Tamilnadu, India by Spectroscopic Studied” BAOJ Physics 2:04, 2:021.

Satya, P., Velraj, G., (2011). "FT-IR spectroscopic and X-ray diffraction analysis of archaeological grey potteries excavated an Alagankulam, Tamilnadu, India” Journal of Experimental Science Vol. 2, Issue 5, pp. 04-06.

7 Drebushchak, V. A., Ljudmila N, Mylnikova., Molodin, V.I., (2007). "Thermogravimetric investigation of ancient ceramics Metrological analysis of
3.

The FT-IR method revealed the presence of ochre in the samples, which probably was a very important feature of the technology for coloring of the samples. The very fact that ochre revealed from this site is interesting and further research into this topic will be done in our next research.

\section{Acknowledgements}

The research was partly financed under the project ShuSS 2017/63 from the Science and Technology Foundation of Mongolia. Suvd-Erdene B. received the Master scholarship from TWAS research grant RGA No: 17-521RG/PHYS/AS_G.

(2)

sampling” Journal of Thermal Analysis and Calorimetry, Vol. 90,1, pp. 73-79.

Van Klinken, J., (2011). “ Magnetization of ancient ceramics ” Archaeometry 43, 1, pp. 49-57.

Suvd-Erdene, B., Orgil, B., Tengis, S., Eregzen, G., Ishtseren, L., Saran, S., (2018). "Analysis of archaeological ceramics using RHX and SEM-EDX" Prints of Institute of Physics and Technology, № 45, pp. 124-132.

10 Maniatis, Y., Facorellis, Y., Pillali, A., and Papanthimou-Papaefthimiou, A., (2002). "Firing temperature determinations of low fired clay structures" Modern Trends in Scientific studies an Ancient Ceramics BAR International Series 1011, pp. 59-68

11 Saran, S., Tengis, S., Orgil, B., (2016). "First results of the rehydroxylation study on firedceramics". Preprints of the Institute of Physics and Technology, 43, pp. 143-148.

12 Saran, S., Tengis, S., Nyamdorj, D., Enkhbat, G., and Turbat, Ts., (2019). "Analysis of lacquer cup from the Xiongnu grave in Tamir valley, Mongolia" Теория и практика археологических исследований УДК 903.5 (517), pp. 4452.

13 Amartuvshin, Ch., Sasada, T., Eregzen, G., Usuki, I., Ishtseren, L., (2012) "History of Xiongnu manufacturing complexes investigation," Studia Archaeologica 
Institute Archaeologici Academiae Scientiarum Mongolicae. Tomus XXXII, Fasciculus 13, pp. 203-228.

14 Ishtseren, L., Sasada, T., (2014) "To the issue on the iron production of the XIONGNU," Studia Archaeologica Institute Archaeologici Academiae Scientiarum Mongolicae. Tomus XXXIV Fasciculus 20, pp. 253-260.

15 Drebushchak, V. A., Mylnikova, L. N., Drebushchak, T. N., (2011). "The mass loss diagram for the ancient ceramics” $\mathrm{J}$ Therm Anal Calorim 104, pp. 459-466.

16 Shoval, S., Beck, P., (2005). “Thermo-FTIR spectroscopy analysis as a method of characterizing ancient ceramic technology" Journal of Thermal

Analysis and Calorimetry. Vol . 82, pp. 609-616.

17 Buxeda I Garrigos, J., Mommsen, H., Tsolakidou, A., (2002). "Alterations of Na, $\mathrm{K}$ and $\mathrm{Pb}$ concentrations in Mycenaean pottery and a proposed explanation using X-ray diffraction” Archaeometry 44, 2, pp. 187-198.
18 Neff, H., (2012). “Comment: Chemical and mineralogical approaches to ceramic provenance determination " Archaeometry 54, 2, pp. 244-249.

19 Fatima Elbashir Siddig., Abdalla Ahmed Elbashir and Verena Lepper., (2019). "Multi Analytical approach for characterization of Archaeological Mercatic potsherds" Int. J. Exp. Spectroscopic Tech 4: p. 023.

20 Genestar, C., Pons, C., (2005). “ Earth pigments in painting: characterisation and differentiation by means of FT-IR spectroscopy and SEM-EDS microanalysis” Anal, Bioanal Chem 382: pp. 269-274.

21 Shoval, S., Yadin, E., Panczer, G., (2011). "Analysis of thermal phases in calcareous Iron Age pottery using FT-IR and Raman spectroscopy” J Therm Anal Calorim 104: pp. 515-525.

22 Vaculikova, L and Plevova, E (2005). "Identification of clay minerals andmicas in sedimentary rocks" Acta Geodyn. Geomater., Vol.2, No.2 (138), pp. 167-175 